\title{
State-of-the-art and future development of sensible heat thermal electricity storage systems
}

\author{
Alberto Benato*, Anna Stoppato, Alberto Mirandola \\ Department of Industrial Engineering, University of Padova, Via Venezia, Padova, Italy \\ Email: alberto.benato@unipd.it
}

\begin{abstract}
Wind and solar energy have a variable and intermittent nature, a characteristic which forces fossil fuel thermal power plants to be used as backup units for grid stabilization. The development and installation of large-scale cost-effective energy storage systems is necessary to adapt electricity generated by renewables to the users' demand. But, the installation of conventional energy storage can add new capacity and further reduce the thermal power plants operational utilization factor. For these reasons, Integrated Energy Storage Systems need to be developed and installed. Pumped Thermal Electricity Storage (PTES) is an emerging technology which can offer a significant contribution to future large-scale electric storage applications. It is based on a high temperature heat pump cycle, which transforms electrical energy into thermal energy and stores it inside two thermal reservoirs, matched with a thermal engine cycle, which converts the stored thermal energy back into electrical energy. The thermal energy is stored as sensible heat in man-made reservoirs, one hot and one cold. In the present work, a detailed analysis of the available PTES configurations is presented underlining advantages, drawbacks and future development. Then, an innovative integrated energy storage unit is presented and compared with the existing ones.
\end{abstract}

Keywords: Energy Storage, Pumped Thermal Electricity Storage, PHS, CAES.

\section{INTRODUCTION}

The world energy demand is rising year by year due to the rapid growth of population, urbanization and industrialization. But, more than $85 \%$ of this demand is covered by fossil fuels: non-renewable sources whose use creates environmental, economic and political issues. For these reasons, in the last decades, several researchers have investigated environmental friendly technologies able to produce energy from renewable energy sources (RES). In this way, the utilization of RES has become more and more important and hundreds of new RES plants, mainly fed by wind and solar, have been installed.

Despite their environmental friendliness, wind and solar are highly variable, uncontrollable and to some extent unpredictable, characteristics which cause large fluctuations in daily, monthly or even annually power production. This aspect forces thermal plants to be used as backup units for grid stabilization in periods of low or no RES production. Then, thermal power plants capacity cannot be completely replaced by renewables, thus resulting in an installed overcapacity of power generation plants [1].

This overcapacity has caused two main consequences [2]: on the one hand, existing thermal power plants are underutilized and their operational utilization factors tend to decline with the increasing quota of wind and solar units.
On the other hand, large-scale Energy Storage Systems (ESS) are required to stabilize the electricity grid but their installation results in additional overcapacity. Therefore, "Integrated Energy Storage System" (I-ESS) in which the underutilized thermal plant units become a part of the ESS need to be studied and developed. In this way, the installation of the large-scale storage unit does not result in additional overcapacity but guarantees to satisfy the need of network flexibility in terms of load levelling [3,4].

Available large-scale Electricity Storage Technologies (ESTs) such as Pumped Hydro Storage (PHS) or Compressed Air Energy Storage (CAES) suffer of geographical constrains, high capital cost and are difficult to integrate in existing thermal power plants while sensible heat Pumped Thermal Electricity Storage (PTES) systems can become a valuable technology able to store large quantity of energy and capable to be integrated in conventional thermoelectric units. For these reasons, in the present work, the storage technologies are firstly presented in Section 2. Then, in Section 2.1 the main characteristics of the available large-scale ESTs are presented while, in Section 2.2, the Pumped Thermal Electricity Storage technology is described underlining advantages, drawbacks and future developments. In Section 3, an innovative I-ESS configuration, developed by the Authors, is presented while, in Section 4, conclusion remarks are given. 


\section{ENERGY STORAGE TECHNOLOGIES}

An Energy Storage (ES) is a device or system in which energy can be stored in some form and, then, can be drawn subsequently, to perform some useful operation. In fact, a complete storage process is mainly composed by three steps: charging, storing and discharging. Some of the steps can occur simultaneously and each step can be done more than once in each storage cycle [5].

All forms of energy (i.e. chemical, potential, kinetic, electrical or thermal) can be stored using an appropriate technology but each ES has a suitable range of application. Therefore, ESTs can be integrated at different levels of the electricity system: generation, transmission, distribution or customer level and, based on the storage applications, the storage technologies can be used for low- or medium- power application for isolated areas, power quality applications or networks peak levelling.

Several storage technologies are available: flywheels, super capacitors, batteries and flow batteries, Compressed Air Energy Storage, Superconducting Magnetic Energy Storage, Pumped Hydro Storage, Pumped Thermal Electricity Storage and hydrogen storage, each one having its own advantages, drawbacks and scale of application. However, despite the large number of ESTs, none of them meets all the requirements of the ideal energy storage system (maturity, long lifetime, low cost, high density, high efficiency and environmental friendliness) and only few of them (PHS, CAES, Flow batteries, PTES and Hydrogen Storage) can be considered large-scale electricity storage technologies (>100 MWh).

\subsection{Available large-scale electricity storage technologies}

Pumped Hydro Storage or Pumped Hydro Energy Storage is a well-known and commercially available technology which has been used for large-scale electricity storage since the 1890s. PHS consists in managing the gravitational potential energy of water, which is stored in reservoirs at different elevations. When the power demand is low, excess generation capacity is used to pump water from the lower to the upper reservoir while, during high peak demand hours, water is released back into the lower reservoir through a turbine. Obviously, the energy stored (up to several GWh) is proportional to the water volume in the upper reservoir and the height of the waterfall [6].

This storage technology can respond to load changes within seconds. Therefore, it can help control the electric network frequency, provide reserve generation, improve grid stability and support the development of intermittent RES. PHS is the dominant large-scale EST, with over $99 \%$ of the world's installed storage capacity, and is characterized by an energy density and a price per stored energy unit in the range $0.5-1.5$ $\mathrm{kWh} / \mathrm{m}^{3}$ and $10-70 € / \mathrm{kWh}$, respectively [7].

Nevertheless, the high initial cost, the geographical constraints and, in some cases, the noteworthy environmental impact caused a rapid commercial development only in Countries with favorable morphology. For a clear survey on existing global PHS capacities, technological development and hybrid systems coupling wind-hydro, solar PV-hydro, wind-PV-hydro, etc. see, e.g., [8] while for a historical overview of the developed PHS units installed in several electricity markets refer, for example, to [9].

The idea of storing electrical energy by means of compressed air (Compressed Air Energy Storage) was proposed in the early 1940s [10] but was immediately abandoned due to the lack of necessity of grid connected energy storage. In 1969, the need of storage capacity in northern Germany forced the decision of developing the first CAES plant in Huntorf [11]. This project stimulated the interest on CAES technology and, from the late 1970s, in Europe and USA several initiatives on both R\&D and predemonstration program of CAES were stated.

The basic concept of CAES is simple. The off-peak power is taken from the grid and used to pump air into a storage volume at high pressure. In practice, the electricity is used to drive compressors which convert the electric energy into potential energy of pressurized air. The storage volume can be of any kind: man-made (tanks) or natural (underground caverns). During peak demand hours, the compressed air is drawn from the storage and expands in air turbines. Turbines are connected to an electric generator which produces electricity.

Several types of Compressed Air Energy Storage systems exist at different stages of development: Diabatic CAES, Adiabatic CAES with and without Thermal Energy Storage (TES) and Isothermal CAES. For a clear overview on CAES technology refer to, e.g., [12-15].

Compressed Air Energy Storage is probably the leading competitor to Pumped Hydro Storage due to the very low selfdiscarded time, the long life ( $>40$ years), the high energy efficiency $(>70 \%)$ and the capacity of storing several hundreds of MWh. CAES is characterized by an energy density of 3-6 kWh $/ \mathrm{m}^{3}$ [7] and a price per stored energy unit of $2-140 € / \mathrm{kWh}$ [7]. In addition, it is expected to have a rapid commercial development especially in Countries with favorable geology, such as USA, because the plant economic feasibility is reached only when a natural underground cavern is used as storage volume.

Flow Batteries are a relatively young technology, which employs two different aqueous electrolytic solutions contained in separate tanks [6]. The operating principle is based on reversible electrochemical reactions that occur in a set of cells. During the years, different types of batteries have been proposed and tested. Hence, several works are available in the scientific literature and can be used to determine the actual state-of-the-art and research fields, e.g. [16-18]. Flow batteries offer a storage capacity of several hundreds of $\mathrm{MWh}$, can become fully discharged without any damage and are characterized by a low self-discharge. However, compared to Pumped Hydro Storage and Compressed Air Energy Storage, flow batteries provide a limited output power and are still expensive. In fact, as summarized in [7], flow batteries are characterized by an energy density of $16-500 \mathrm{kWh} / \mathrm{m}^{3}$ and a price per stored energy unit in the range $75-2000 € / \mathrm{kWh}$.

To sum up, Pumped Hydro Storage will remain the dominant Energy Storage Technology at least in the very near future while Compressed Air Energy Storage is expected to have a rapid commercial development as for Flow Batteries. However, limitations in terms of geographical constraints, high capital cost or low cycle life are stressing the necessity of developing new energy storage technologies not only able to store large quantity of energy but also capable to be integrated into conventional thermal power units. Only in this manner, it is possible to install Energy Storage Systems without increasing the electricity system overall capacity and revamp old and/or underutilized thermoelectric power plants. 


\subsection{In-developing large-scale ESTs}

Hydrogen storage and Pumped Thermal Electricity Storage are considered promising large-scale ESTs.

Storing electricity surplus as hydrogen is an energy storage option especially when longer-term season-to-season storage is needed. Generally speaking, a conventional hydrogen-based electrical energy storage system comprises an electrolyser, a hydrogen storage system (such as compressed gas or in solidstate as a metal hydride) and a fuel cell while in new architectures the proton flow battery has been adopted to reduce the number of separate components and to achieve a higher round-trip energy efficiency, and gravimetric and volumetric energy density [19]. Several works are available in the scientific literature but all of them underline the need of developing safer and efficient hydrogen storage system with acceptable volumetric energy densities. For this reason, hydrogen storage could become economically feasible around 2030 [20] but it is expected that this technology has an energy density in the range $2.7-160 \mathrm{kWh} / \mathrm{m}^{3}$ and a price per stored energy unit of $2-15 € / \mathrm{kWh}[7]$.

Pumped Thermal Electricity Storage is based on a high temperature heat pump cycle, which transforms electrical energy into thermal energy and stores it inside two thermal reservoirs, followed by a thermal engine cycle, which transforms the stored thermal energy back into electrical energy. The thermal energy is stored as "sensible heat" in two man-made thermal reservoirs, one hot and one cold. Based on the available works, PTES is characterized by high thermal losses and irreversibility but is free from geographic constraints (which affect PHS and CAES), does not suffer of output power limitation (such as flow batteries) and benefits from relatively high energy density $\left(50 \mathrm{kWh} / \mathrm{m}^{3}\right.$ [7]), which should bring a low cost per MWh of storage capacity and a small installation footprint.

As said, in PTES units the electricity is converted into thermal energy and stored into man-made reservoirs. Therefore, the core of the ESS is the Thermal Energy Storage (TES). This is a widely-adopted technology which is applied to a broad spectrum of applications, such as industrial, commercial and residential heating and cooling, but it is a novelty for electricity generation applications. In TES units, suitable materials are placed within man-made insulated tanks. During the charging phase, electricity is used to heat/cool the containment material, up to a suitable temperature. The thermal energy stored in the insulated containment can be recovered and converted again into electricity using heat engine cycles (delivering phase).

TES systems suitable for large-scale storage can be classified as: Cryogenic Systems, Pumped Heat Storage Systems and Hybrid Systems.

In a Cryogenic System, energy is stored in tanks of liquid air or liquid nitrogen. Using off-peak power sources or electricity produced with renewable or directly mechanical work from hydro or wind turbines, liquid nitrogen or liquid air can be produced and electricity stocked as a cryogenic fluid. During high peak demand hours, the heat of the environment is used to boil this fluid. Then, a cryogenic heat engine is used to produce electricity from the heated cryogen. This technology has a relatively high energy density (100-200 $\mathrm{Wh} / \mathrm{kg}$ ) and a quite long storage period but also low capital cost per energy unit. The main issue is the relatively low efficiency (40-50\%) caused by the energy consumption for air liquefaction. At the time of writing, Cryogenic Energy Storage
Systems can be considered an under developing technology that several research groups around the world are studying (e.g. [21]).

High temperature reservoirs are used to store energy in Pumped Heat Storage Systems while Hybrid Systems simultaneously adopt both hot and cold thermal storage.

In PTES or Pumped Heat Storage System, thermal energy can be stored as "sensible heat", "latent heat" or "chemical energy". In sensible heat storage, heat is stored by increasing the storage medium temperature while in latent heat storage systems the energy is stored in phase change materials. In particular, the heat is stored when the material changes its phase from solid to liquid. When the storage process involves chemical reactions, the adopted storage is a thermochemical one. Sensible heat storage is used in pebble bed, packed bed or molten salts for thermal solar power plants, water heater storage, blast or glass furnace regenerators, and for building heating and cooling. Latent heat storage is used in buildings for passive storage systems such as phase change material walls, wallboards, and shutters, in solar latent heat storage unit, or for the cooling of transient thermal load of electronic devices. Despite the variety of arrangements, sensible heat storage is the most simple and inexpensive way to store energy although there are few advantages of phase change energy storage over sensible heat storage, but the technological and economic aspects make sensible heat storage more suitable and attractive for large-scale EES.

Being the aim of the present work to analyze the current state-of-the-art of the PTES technology, an in-depth literature survey is presented in the following.

In the last decades, several independent patents have been filed. Therefore, a lot of plant versions are available for the so called "Pumped Thermal Electricity Storage" or "Pumped Heat Electricity Storage".

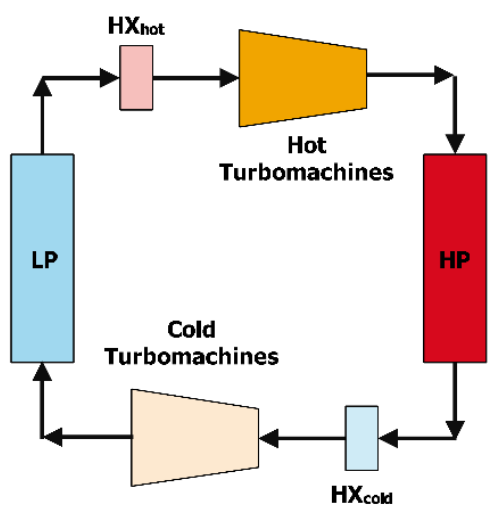

Figure 1. PTES unit proposed in [30]

The first PTES layout was proposed in 1979 [22]. It consists of an open cycle made of a compressor, a turbine and a thermal accumulator plus a recuperator. During the charging time, the regenerator is located upstream to the compressor while, for discharge, it is located downstream from the turbine. In 2007, Wolf [23] patented a method for storing and recovering electric energy based on a circulatory process while Chen et al. [24] presented an invention concerning systems to store energy and using it to generate electrical energy or drive a propeller. From 2008 to 2016, several other patents have been registered with alternative PTES configurations [25-29] but, 
apart from patents, in literature, only few theoretical works analyze the PTES technology from a scientific point of view.

Desrues et al. [30] presented a thermal energy storage process for large scale electric applications (Figure 1).

The system is based on a high temperature heat pump cycle, which converts electrical energy into thermal energy and stores it inside two large regenerators, followed by a thermal engine cycle, which recovers the stored thermal energy back into electrical energy. The system arrangement consists of a high and a low-pressure tank (HP and LP), four turbomachines and two heat exchangers, one hot $\left(\mathrm{HX}_{\mathrm{hot}}\right)$ and one cold $\left(\mathrm{HX}_{\text {cold }}\right)$. There is the need of including four turbomachines because one compressor/turbine pair is used during the loading period while another one during the delivery phase. The tanks are regenerators, made of refractory material, which alternatively store or deliver heat. The fluid medium is a gas, Argon, which circulates within a closed thermodynamic Brayton cycle. The initial temperature of the $\mathrm{HP}$ tank is $25^{\circ} \mathrm{C}$ while the $\mathrm{LP}$ one is $500^{\circ} \mathrm{C}$. During the charging period, the HP tank is heated from $25^{\circ} \mathrm{C}$ up to $1000^{\circ} \mathrm{C}$ while the $\mathrm{LP}$ one is cooled from $500^{\circ} \mathrm{C}$ to $-70^{\circ} \mathrm{C}$. The two heat exchangers are fundamental because they are used to maintain the compressor and turbine inlet temperature at a constant value of $500^{\circ} \mathrm{C}$ and $25^{\circ} \mathrm{C}$, respectively. The two man-made tanks have a total volume of $21622 \mathrm{~m}^{3}$ while the pressure in the HP and LP tanks is maintained at 4.6 bar and 1 bar, respectively. Desrues et al. developed a numerical model that shows the feasibility of the process, even with sub-optimal parameters, basic geometry, and laminar convective heat transfer. Using numerical simulations, Desrues et al. computed the loading and delivering duration ( $6 \mathrm{~h} 3 \mathrm{~min}$ and $5 \mathrm{~h} 52 \mathrm{~min}$ ), the storage capacity (602.6 MWh) and the storage efficiency $(66.7 \%)$. Finally, they concluded that a model validation is requested using a test loop that includes two sufficiently large regenerators.

Howes [31] developed a hypothetical 2 MW PTES system with $16 \mathrm{MWh}$ of storage. The system is based on the early conceptualization of a system, developed in 1833 by John Ericsson, for reversible heat/work conversion and based on a heat engine cycle in combination with utility scale thermal energy storage made of mineral (e.g., gravel). A mathematical model has been built during the investigation and simulation results have been used to predict the performance of the utility scale equipments.

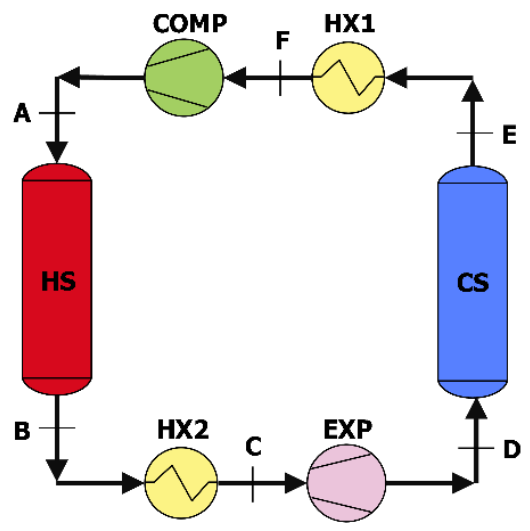

Figure 2. PTES unit proposed in [33]

Thess [32] performed a theoretical work that includes "endoreversible" analysis of a generic system while White et al. [33] and McTigue et al. [34] studied thermodynamic aspects of Pumped Thermal Electricity Storage.

White et al. [33] analyzed PTES thermodynamic aspects, including energy and power density, and the various sources of irreversibility and their impact on round-trip efficiency. The system scheme is depicted in Figure 2.

The main components of this ESS are a compressor (COMP), an expander (EXP) and two thermal storages: one hot (HS) and one cold (CS). The thermal storage systems are arranged vertically; the energy is stored as sensible heat and the working fluid is a gas (Argon as proposed in [31]). The heat exchangers (HX1 and HX2) serve mainly to reject heat from the cycle (via cooling water), this being required to counter-balance the effects of system irreversibilities [33]. As remarked in [33], the paper presents a simplified model of the PTES unit which provides a basic understanding of how the main operating conditions and loss parameters influence the performance. The analysis reveals that both the round-trip efficiency and the storage density increase with the compressor temperature ratio. However, high temperature ratios imply high pressure ratios which in turn bring high cost of the hot reservoir. This aspect can be mitigated using a monatomic gas such as Argon as working fluid. White et al. also underlined that a satisfactory round-trip efficiency can be achieved using reciprocating machines instead of turbomachinery-based devices. The effects of compression and expansion irreversibility can be mitigated by reducing the ratio between hot and cold store discharged temperatures, which also has the advantage of increasing the energy and power density.

McTigue et al. [34] analyzed the thermodynamic aspects of Pumped Thermal Electricity Storage, too. The plant scheme, depicted in Figure 3, is similar to the one proposed in [33] but, the developed model is based on steady flow analysis of the compression and expansion devices coupled with a Schumann-style model of the hot and cold thermal stores.

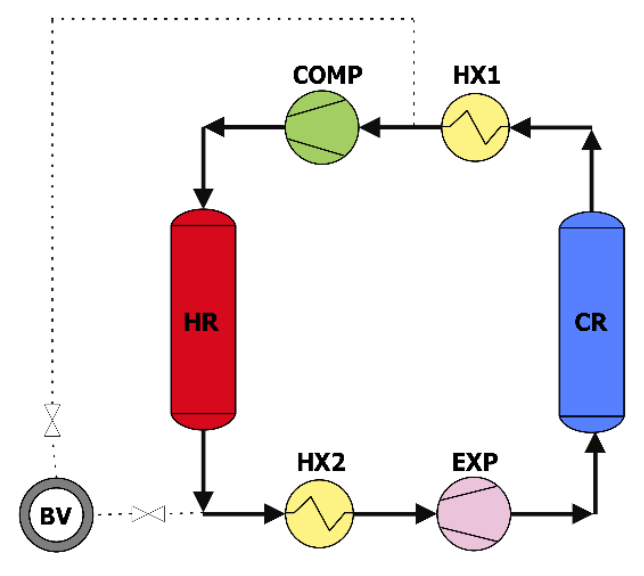

Figure 3. PTES unit proposed in [34]

An additional important feature of the performed analysis is that sources of exergetic loss have been considered in detail with the attempt to identify the maximum round-trip efficiency that can be achieved. The main system components are two compression/expansion devices (COMP and EXP) and two thermal reservoirs (one hot, HR, and one cold, CR) while the working fluid is, again, Argon. The hot reservoir has a volume of $71 \mathrm{~m}^{3}$, an internal diameter of $4.5 \mathrm{~m}$ and works at a pressure of $10.5 \mathrm{bar}$ and a temperature of $505^{\circ} \mathrm{C}$. Conversely, the CR has a volume of $117 \mathrm{~m}^{3}$, an internal diameter of $5.3 \mathrm{~m}$ and 
works at a pressure of 1.05 bar and a temperature of $-150^{\circ} \mathrm{C}$. The storage material is $\mathrm{Fe}_{3} \mathrm{O}_{4}$ in the form of a packed bed with an assumed void fraction of 0.35 . The system is designed for a storage capacity of $16 \mathrm{MWh}$ as the one presented in [31]. Note that, in addition to the main components, the system requires two heat exchangers (HX1 and $\mathrm{HX} 2$ ), and a buffer vessel (BV). The heat exchangers are needed to counterbalance the effects of irreversibility while the buffer vessel is introduced because the total mass of gas within the two reservoirs changes during the charging period. The analysis reveals that the round-trip efficiency is influenced by the loss factors that occur in compression and expansion processes during the charge and the discharge cycle. To better understand the problem, McTigue et al. performed a multiobjective optimization to generate the trade-off surfaces that show the round-trip efficiency vs. the energy density curve. These curves are relatively flat over a considerable range, so high energy density can be attained with only a modest efficiency penalty. In the optimized design, the losses caused by the pressure drop and the irreversible heat transfer in the stores are only a few percent, so the success of PTES is likely to hinge upon compressor and expander performance.

Morandin et al. $[35,36]$ presented a new conceptual design of a thermoelectric energy storage while a performance evaluation of a PTES, a PCES and a Brayton PTES system have been proposed by Guo et al. [37,38].

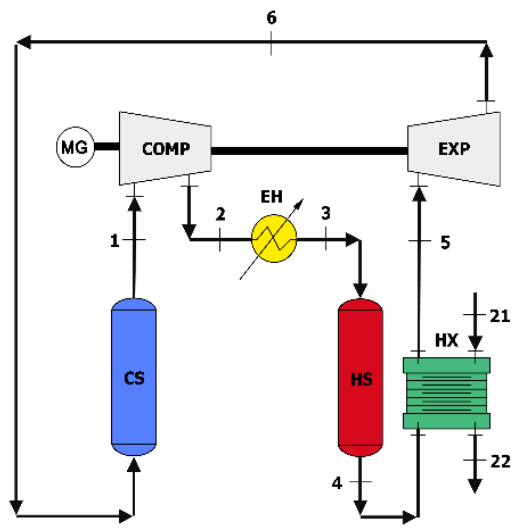

(a) Plant scheme adopted during charging period

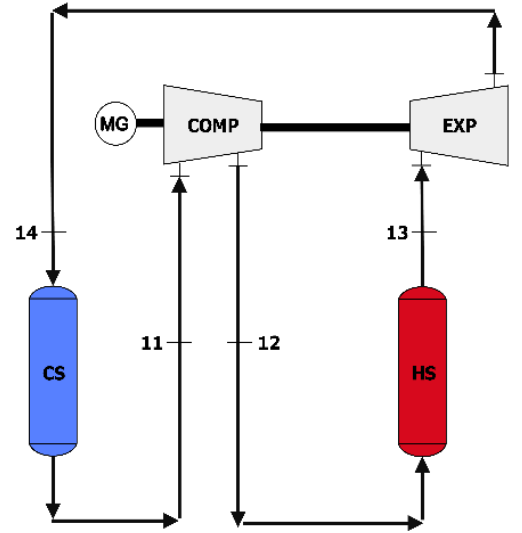

(b) Plant arrangement used during delivery period

Figure 4. New PTES plant architecture

Finally, also the Authors of the present work presented a modified version of the PTES system in which electricity is converted into heat using an electric heater and only one heat exchanger is required. The system layout during charge and discharge is depicted in Figure 4 (charge Figure 4(a), discharge Figure 4(b)).
The system consists of a high pressure and temperature tank (HS) and a low pressure and temperature tank (CS), two turbomachines (a compressor, COMP, and a turbine, EXP), an electric motor/generator (MG), an electric heater $(\mathrm{EH})$ and a heat exchanger (HX) used as a cooler. The adopted working fluid is air and not argon as in $[31,33,34]$ while electrical energy is stored as sensible heat. During the charging phase (Figure 4(a)), the turbomachines force the air to follow the route $1,2,3,4,5$ and 6 which does not correspond exactly to a heat pump transferring heat from CS to HS because, after the compressor, there is an electric heater. This component is used to maintain $T_{3}$ equal to the maximum cycle temperature $T_{\max }$. Therefore, the fluid temperature is not increased using the irreversibility of the compression process. Then, high temperature does not mean high pressure ratio which in turns implies low purchasing costs for the compressor and the HS.

During the delivery period (Figure 4(b)), the gas flows along the route 11, 12, 13 and 14 which corresponds to a heat engine cycle. The air that leaves the compressor, enters the HS tank, is heated up and leaves the HS at the maximum cycle temperature. Then, the air is expanded using the turbine and injected into the CS tank. Here, it is cooled and, when it leaves the CS, its temperature is equal to $\mathrm{T}_{\min }$. Similarly, to the charging phase, the CS tank material is slowly heated up by the warm gas that leaves the expander while the HS tank material is slowly cooled down by the air coming from the compressor. To better investigate the heat transfer process between the working fluid and the packed bed, the Authors built a detailed model of the tank and tested different storage materials with different shapes. Despite the poor round-trip efficiency, the proposed PTES system is able to compete with CAES, PHS and batteries in term of price per energy unit stored and energy density. If the compression pressure ratio is equal to 6, each tank has a volume of $150 \mathrm{~m}^{3}$, alumina oxide spheres are used as storage material, the maximum cycle temperature is in the range $550-1050^{\circ} \mathrm{C}$ and the minimum cycle temperature is $-70^{\circ} \mathrm{C}$, the energy density is in the range $70-430 \mathrm{kWh} / \mathrm{m}^{3}$ while the price per stored energy unit is between 50 and $180 € / \mathrm{kWh}$.

In the above-mentioned works, different storage materials have been proposed to store the energy as sensible heat. Therefore, the selection of the storage medium is a fundamental step during the design of a PTES unit.

PTES systems employ gaseous substances as working fluid; then, the most suitable storage unit is a packed bed system [39]. A packed bed storage system consists of loosely packed solid material through which the heat transport fluid is circulated. A packed bed generally represents the most suitable and widely adopted energy storage unit for air based solar systems. Therefore, a packed bed storage is a well-established technology. The optimum size of the storage system is a function of several parameters such as storage temperature and material, storage heat losses and storage container cost, heat exchangers, cost of auxiliary energy and operating conditions [39]. The storage medium needs to be inexpensive, non-toxic, non-flammable, with high thermal diffusivity and good conductive characteristics. Solid storage materials, such as rocks, metals, concrete, sand and brick are preferable because they can be used for low as well as high temperature thermal energy storage. Obviously, to minimize the heat exchangers cost, in a solid storage medium, a direct contact between the solid storage material and the heat transfer fluid is required to reduce the storage heat transfer area as well as an appropriate storage insulation system and a relative small distance 
between the storage systems and the compressors/turbines. For more details about numerical and experimental investigations conducted on packed bed energy storage systems, see, for example, [39].

Based on the above literature survey, it is possible to claim that all the presented large-scale energy storage technologies are conventional ESS and not Integrated ones. Therefore, installing this kind of plants can result in additional overcapacity which can reduce the existing thermal plants operational utilization factors. However, the devices of a conventional PTES unit and of a gas turbine (GT) can be used to arrange an I-ESS. In this manner, it is possible to revamp existing power units characterized by low operational utilization factors in integrated energy storage systems which satisfy the pressing need of network flexibility without installing additional capacity.

\section{I-ESS CONFIGURATION}

The architecture of the novel I-ESS plant is shown in Figure 5 (Figure 5(a): charge, Figure 5(b): delivery). This plant layout is part of a patent proposal and the object of ongoing research activities [40, 41].

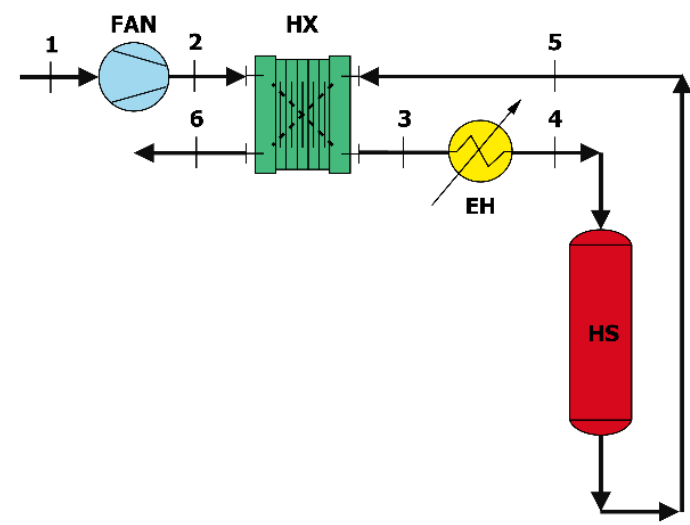

(a) Plant scheme adopted during charging period

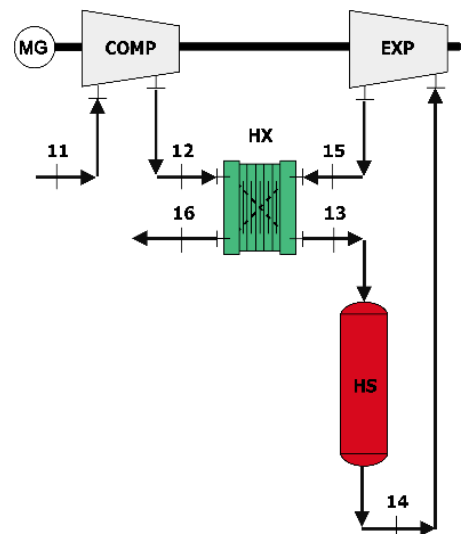

(b) Plant arrangement used during delivery period

Figure 5. I-ESS plant scheme

The system consists of a high pressure and temperature tank (HS), a fan (FAN), an electric heater (EH), two turbomachines (a compressor, COMP, and a turbine, EXP), an electric motor/generator (MG) and a heat exchanger (HX). The adopted working fluid is a gaseous medium, air, while electrical energy is stored as sensible heat. During the charging phase (Figure 5(a)), the fan forces the air to follow the route 1, $2,3,4,5$ and 6 . The electric heater is the device which converts the electrical energy into thermal energy and it is used to maintain $T_{4}$ equal to the maximum cycle temperature $T_{\max }$. This is one of the novelties of the proposal because in similar plant configurations $[31,33,34]$, the maximum working fluid temperature, which corresponds to the maximum temperature of the cycle $\mathrm{T}_{\mathrm{A}}$ (see Figure 2), is reached at the compressor outlet section. Therefore, the compressor process is used to increase the temperature of the gas. Hence, to reach high temperature, high pressure ratio is needed.

To overcome this issue, in [31,33,34], a heat exchanger (called HX1 in Figure 2) is used to maintain $\mathrm{T}_{\mathrm{F}}$ at a prefixed value independent to the value assumed by $\mathrm{T}_{\mathrm{E}}$. Subsequently, $\mathrm{T}_{\mathrm{F}}, \mathrm{T}_{\mathrm{E}}$ and the compression ratio remain constant during the entire charging phase. High temperature ratio implies high pressure ratio, an effect mitigated in previous works by the adoption of a high value of $\mathrm{T}_{\mathrm{F}}$ (equal to $500^{\circ} \mathrm{C}$ in [31]) or a low value of $\mathrm{T}_{\mathrm{A}}\left(-70^{\circ} \mathrm{C}\right.$ in [34]). Note that, at the end of the charging phase, $\mathrm{T}_{\mathrm{E}}$ becomes $-150^{\circ} \mathrm{C}$ in $[31]$ and $-70^{\circ} \mathrm{C}$ in [34] while $\mathrm{T}_{\mathrm{F}}$ is $500^{\circ} \mathrm{C}$ and $25^{\circ} \mathrm{C}$, respectively. Therefore, a lot of energy is lost due to the different temperature range. In the proposed scheme (see Figure 5(a)), the electric heater, inserted after the HX, overcomes the above-mentioned issues because $\mathrm{T}_{4}$ is maintained constant and equal to $\mathrm{T}_{\max }$ independently to $\mathrm{T}_{1}, \mathrm{~T}_{2}, \mathrm{~T}_{3}$ and the compressor pressure ratio. This allows to adopt low pressure ratio, high maximum cycle temperature, acceptable cost and heat transfer area. In fact, in the proposal, the charging cycle is an open cycle, a fan is used to circulate the working fluid and only a hot tank is required.

During the delivery period (Figure 5(b)), the gas flows along the path $11,12,13,14,15$ and 16 which corresponds to a modified Brayton cycle. The air that leaves the compressor, enters the HX and, then, into the HS tank, is heated up and leaves the HS at the temperature $T_{\max }$. Subsequently, the air is expanded using the turbine and injected into the HX. Here, it is cooled and, when it leaves the HX, it is released into the ambient. Comparing again the proposed plant scheme with the ones presented in $[31,33,34]$, no cold tank is required during the delivery phase; and this fact reduces both the plant complexity and cost.

The HS tank is arranged vertically to prevent buoyancydriven instabilities of the thermal fronts. It is cylindrical with an upper plenum, a packed bed storage and a lower plenum.

This plant architecture can be considered an innovative IESS because the power unit used during the delivery period is an external combustion Gas Turbine (GT) in which the combustion chamber is replaced by the high temperature sensible heat thermal energy storage. In this way, an existing thermal plant based on the GT technology can be easily revamped into an Integrated Energy Storage System.

The Authors built the mathematical model of the plant using the Mumma and Marvin model reported by Howell et al. $[41,42]$ to predict thermal performance of a packed bed and the equations proposed by Singh et al. $[42,43]$ to estimate the pressure drop in the hot tank. A 3 MW gas turbine and a 500 $\mathrm{m}^{3}$ tank have been considered because these devices are available in an underutilized thermal power unit.

The analysis reveals that using a maximum cycle temperature of $850^{\circ} \mathrm{C}$ and a packed bed made of spheres of aluminum oxide randomly packed, the system requires 22.7 hours for the first charge while from the second to the " $\mathrm{j}$-th" charge and from the first to the " $\mathrm{j}$-th" discharge the requested times are 14.4 hours and 13 hours, respectively. Note that, 
during these 13 hours the output power is $2.5 \mathrm{MW}$ and is relatively constant. Therefore, the plant is able to provide 32.5 MWh with a round-trip efficiency of $20.9 \%$. Considering that the tank and the GT used to convert the stocked energy into electricity are already available devices, the price per energy unit and the energy density can be estimated in $94 \mathrm{Euro} / \mathrm{kWh}$ and $65 \mathrm{kWh} / \mathrm{m}^{3}$; values comparable with the ones of PHS, CAES, Flow batteries and conventional PTES. But, this plant configuration does not add new capacity to the grid, requires a limited number of components and can be easily arranged starting from an existing thermal power unit.

\section{CONCLUSIONS}

Large-scale Integrated Energy Storage Systems need to be developed to compensate the renewable energy sources power fluctuation and reduce the installed overcapacity. For this reason, in the present work, the authors firstly analyzed the available and in-developing energy storage technologies underling advantages and drawbacks. Then, an innovative plant configuration able to be integrated in existing underutilized thermal power units has been presented.

The comparison among PHS, CAES, batteries, PTES and the new scheme shows that the proposal is able to compete with other ESS technologies in term of specific cost and energy density. But, it does not present geographical limitations because the reservoir is a man-made device, has higher cycle life than sodium-sulphur and sodium nickel chloride batteries, can be arranged using existing plant devices and the plant installation does not add new capacity.

Obviously, additional investigations and optimizations need to be performed to find out efficient management strategies, cheaper bed storage material and heat transfer and pressure drop correlations. But, the proposal seams promising.

\section{REFERENCES}

[1] Vinnemeier P., Wirsum M., Malpiece D., Bove R. (2016). Integration of heat pumps into thermal plants for creation of large-scale electricity storage capacities, Appl. Energ., Vol. 184, pp. 506-522. DOI: $\underline{10.1016 / \text { j.apenergy.2016.10.045 }}$

[2] Vinnemeier P., Wirsum M., Malpiece D., Bove R. (2016). Integration of pumped heat electricity storage into water/steam cycles of thermal power plants, $I n: 5 t h$ International Symposium - Supercritical CO2 Power Cycles, San Antonio, Texas.

[3] Chen H., Cong T.N., Yang W., Tan C., Li Y., Ding Y. (2016). Progress in electrical energy storage system: A critical review, Prog. Nat. Sci. Vol. 19, No. 3, pp. 291312. DOI: 10.1016/j.pnsc.2008.07.014

[4] Ibrahim H., Ilinca A., Perron J. (2008). Energy storage systems-characteristics and comparisons, Renew. Sust Energ. Rev., Vol. 12, No. 5, pp. 1221-1250. DOI: 10.1016/j.rser.2007.01.023

[5] Hasnain S. (2009). Review on sustainable thermal energy storage technologies, part I: heat storage materials and techniques, Energ. Convers. Manage., Vol. 39, No. 11. pp. 1127-1138. DOI: 10.1016/S01968904(98)00025-9

[6] Diaz-Gonzalez F., Sumper A., Gomis-Bellmunt O., Villafafila-Robles R. (2012). A review of energy storage technologies for wind power applications, Renew. Sust. Energ. Rev., Vol. 16, No. 4, pp. 2154 2171. DOI: $10.1016 /$ j.rser.2012.01.029

[7] Zhang H., Baeyens J., Caceres G., Degreve J., Lv Y. Thermal energy storage: Recent developments and practical aspects, Prog Energ Comb Sci, Vol. 53, pp. 140.

[8] Rehman S., Al-Hadhrami L.M., Alam M.M. (2015). Pumped hydro energy storage system: a technological review, Renew. Sust. Energ. Rev., Vol. 44, pp. 586-598. DOI: 10.1016/j.rser.2014.12.040

[9] Barbour E., Wilson I.G., Radcliffe J., Ding Y., Li Y. (2016). A review of pumped hydro energy storage development in significant international electricity markets, Renew. Sust. Energ. Rev., Vol. 61, pp. 421432. DOI: $\underline{10.1016 / \text { j.rser.2016.04.019 }}$

[10] Kalhammer F.R., Schneider T.R. (1976). Energy storage, Annu. Rev. Energ., Vol. 1, No. 1, pp. 311-343. DOI: $10.1146 /$ annurev.eg.01.110176.001523

[11] Mattick W., Haddenhorst H., Weber O., Stys Z.S. (1975). Huntorf: the world's first 290-MW gas turbine air-storage peaking plant. [compressed air pumped hydro storage], Proc. Am. Power Conf., Vol. 37.

[12] Budt M., Wolf D., Span R., Yan J. (2016). A review on compressed air energy storage: Basic principles, past milestones and recent developments, Appl. Energ., Vol. 170, pp. 250-268. DOI: 10.1016/j.apenergy.2016.02.108

[13] Venkataramani G., Parankusam P., Ramalingam V., Wang J. (2016). A review on compressed air energy storage-a pathway for smart grid and polygeneration, Renew. Sust. Energ. Rev., Vol. 62, pp. 895-907. DOI: 10.1016/j.rser.2016.05.002

[14] Lund H., Salgi G. (2009). The role of compressed air energy storage (CAES) in future sustainable energy systems, Energ. Convers. Manage., Vol. 50, No. 5, pp. 1172-1179. DOI: 10.1016/j.enconman.2009.01.032

[15] Denholm P., Sioshansi R. (2009). The value of compressed air energy storage with wind in transmission-constrained electric power systems, Energ. Policy, Vol. 37, No. 8, pp. 3149-3158. DOI: 10.1016/i.enpol.2009.04.002

[16] Divya K., Østergaard J. (2009). Battery energy storage technology for power systems-an overview, Electr. Pow. Syst. Res., Vol. 79, No. 4, pp. 511-520. DOI: 10.1016/j.epsr.2008.09.017

[17] Doughty D.H., Butler P.C., Akhil A.A., Clark N.H., Boyes J.D. (2010). Batteries for large-scale stationary electrical energy storage, The Electrochemical Society Interface, Vol. 19, No. 3, pp. 49-53.

[18] Dunn B., Kamath H., Tarascon J.M. (2011). Electrical energy storage for the grid: a battery of choices, Science, Vol. 334, No. 6058, pp. 928-935. DOI: 10.1126/science. 1212741

[19] Andrews J., Mohammadi S.S. (2014). Towards a 'proton flow battery': investigation of a reversible PEM fuel cell with integrated metal-hydride hydrogen storage, Int. J. Hydrogen Energ., Vol. 39, No. 4, pp. 1740-1751. DOI: $10.1016 /$ ij.ijhydene.2013.11.010

[20] Klumpp F. (2016). Comparison of pumped hydro, hydrogen storage and compressed air energy storage for integrating high shares of renewable energies-potential, cost-comparison and Ranking, J. Energ. Storage, Vol. 8, pp. 119-128. DOI: 10.1016/j.est.2016.09.012 
[21] Wen D., Chen H., Ding Y., Dearman P. (2006). Liquid nitrogen injection into water: pressure build-up and heat transfer, Cryogenics, Vol. 46, No. 10, pp. 740-748. DOI: $10.1016 /$ j.cryogenics.2006.06.007

[22] Weissenbach D. (2007). Thermischer kraftspeicher thermal power storage, DE Patent App, DE19, Vol. 782, No. 810, pp. 890-1979.

[23] Wolf B. (2007). Verfahren zur speicherung und ruckgewinnung von energie a method for storage and recoveryof energy, DE Patent App, DE200, Vol. 610, No. 7, p. 119.

[24] Chen H., Ding Y., Peters T., Berger F. (2007). A method of storing energy and a cryogenic energy storage system, CA Patent App, CA, Vol. 2, No. 643, pp. 742.

[25] Ruer J. (2008). Installation et procedes de stockage et restitution d'energie electrique, CA Patent App, CA, Vol. 2, No. 686, p. 417.

[26] Macnaghten J., Howes J. (2009). Energy storage, CA Patent App, Vol. 2, No. 701, CA, p. 526.

[27] Hemrle J., Mercangoez M., Ohler C. (2010). Thermoelectric energy storage system and method for storing thermoelectric energy, WO Patent App, PCT/EP2009/058, p. 914.

[28] Laurberg H. (2012). Thermal energy storage and recovery arrangement, US Patent App, Vol. 14, No. 237, p. 885 .

[29] Samoilov A. (2013). Method for accumulating, storing and recovering mechanical energy and apparatus for the implementation thereof (embodiments), WO Patent App, PCT/RU2013/000, p. 91.

[30] Desrues T., Ruer J., Marty P., Fourmigue J. (2009). A thermal energy storage process for large scale electric applications, Appl. Therm. Eng., Vol. 30, No. 5, pp. 425-432. DOI: $10.1016 /$ j.applthermaleng. 10.002

[31] Howes J. (2012). Concept and development of a pumped heat electricity storage device, Proceedings of the IEEE, Vol. 100, No. 2, pp. 493-503.

[32] Thess A. (2013). Thermodynamic efficiency of pumped heat electricity storage, Phys. Rev. Lett., Vol. 111, No. 11, pp. 110602. DOI: 10.1103/PhysRevLett.111.110602

[33] White A., Parks G., Markides C.N. (2013). Thermodynamic analysis of pumped thermal electricity storage, Appl. Therm. Eng., Vol. 53, No. 2, pp. 291-298. DOI: $\underline{10.1016 / \text { j.applthermaleng.2012.03.030 }}$

[34] McTigue J.D., White A.J., Markides C.N. (2015). Parametric studies and optimisation of pumped thermal electricity storage, Appl. Energ., Vol. 137, pp. 800-811. DOI: 10.1016/j.apenergy.2014.08.039

[35] Morandin M., Marechal F., Mercangoz M., Buchter F. (2012). Conceptual design of a thermo-electrical energy storage system based on heat integration of thermodynamic cycles-part a: Methodology and base case, Energy, Vol. 45, No. 1, pp. 375-385. DOI: $\underline{10.1016 / \text { j.energy.2012.03.031 }}$
[36] Morandin M., Marechal F., Mercangoz M., Buchter F. (2012). Conceptual design of a thermo-electrical energy storage system based on heat integration of thermodynamic cycles-part b: Alternative system configurations, Energy, Vol. 45, No. 1, pp. 386-396. DOI: $10.1016 /$ j.energy.2012.03.031

[37] Guo J., Cai L., Chen J., Zhou Y. (2016). Performance optimization and comparison of pumped thermal and pumped cryogenic electricity storage systems, Energy, Vol. 106, pp. 260-269. DOI: 10.1016/j.energy.2016.03.053

[38] Guo J., Cai L., Chen J., Zhou Y. (2016). Performance evaluation and parametric choice criteria of a Brayton pumped thermal electricity storage system, Energy, Vol. 113, pp. 693-701. DOI: 10.1016/j.energy.2016.07.080

[39] Singh H., Saini R., Saini J. (2010). A review on packed bed solar energy storage systems, Renew. Sust. Energ. Rev., Vol. 14, No. 3, pp. 1059-1069. DOI: 10.1016/j.rser.2009.10.022

[40] Benato A., Pezzuolo A., Stoppato A. (2016). Impianto e metodo per l'accumulo di energia e la successiva produzione di energia elettrica, Italian Patent.

[41] Benato A. (2017). Performance and cost evaluation of an innovative Pumped Thermal Electricity Storage power system, Energy, Vol. 138, pp. 419-436. DOI: 10.1016/j.energy.2017.07.066

[42] Howell J.R., Bannerot R.B., Vliet G.C. (1982). Solarthermal energy systems: analysis and design, McgrawHill College.

[43] Singh R., Saini R., Saini J. (2006). Nusselt number and friction factor correlations for packed bed solar energy storage system having large sized elements of different shapes, Solar Energy, Vol. 80, No. 7, pp. 760-771. DOI: 10.1016/j.solener.2005.07.001

\section{NOMENCLATURE}

CAES
ES
ESS
EST
GT
I-ESS
PHS
PTES
RES
T
TES

Compressed Air Energy Storage Energy Storage

Energy Storage System Electricity Storage Technology Gas Turbine

Integrated Energy Storage System Pumped Hydro Storage Pumped Thermal Electricity Storage Renewable Energy Sources Temperature Thermal Energy Storage

\section{Subscripts}

$\max \quad$ maximum

$\min \quad$ minimum 